\title{
WSSA Position Statements on Timely Issues
}

During the past several years, WSSA has become more proactive regarding a number of timely issues that impact either directly or indirectly on weed science and societal affairs. Notable among the activities of WSSA is the preparation of "position statements", which upon approval of the Executive Committee of WSSA are then presented by certain officers and other representatives of WSSA to appropriately targeted audiences within the Congress, USDA, EPA, and/or other agencies or branches of government. These efforts, traditionally highlighted by an annual visit to Washington, DC, have proved to be very beneficial for all parties concerned.

The eight position statements developed for 1992, and alluded to by Past President John R. Abernathy and President Joe Antognini in recent issues of the WSSA Newsletter, are published below in their entirety as a matter of timely interest to all members of WSSA. For further information, contact Dr. Joe Antognini, President, WSSA.

Editor

June, 1992

\section{OVERVIEW}

Weeds are undesirable terrestrial and aquatic plants that negatively affect (1) the productivity of farmland and forests, (2) human and animal health, and (3) the beauty and utility of gardens, lawns, parks, lakes, rivers and other residential, recreational and commercial areas. Weeds are competitive, pernicious and persistent.

Members of the Weed Science Society of America and its affiliates represent a wide range of disciplines from organizations such as:

$\begin{array}{ll}\text { Colleges and Universities } & \text { Agency personnel } \\ \text { Pesticide manufacturers } & \text { Pesticide distributors/dealers } \\ \text { Pesticide applicators } & \text { Contract research services } \\ \text { Agricultural consultants } & \text { Equipment manufacturers } \\ \text { Farm operators } & \text { Agricultural news media }\end{array}$

Weed Scientists are sources of information on issues relating to:

Biology, ecology and physiology of weeds. Crop/animal and human health losses due to weeds. Impact of weeds on crop production.
Herbicides for weed management in sustainable agriculture.

Herbicide-resistant weeds and crops.

Herbicide selectivity on crops.

Mechanisms of action of herbicides.

Fate of herbicides in soil and water.

Integrated weed management.

Weeds as environmental pollutants.

Biological agents for weed management.

WSSA position statements on matters of concern are prepared annually. Those presently available are:

1. Food Safety

2. Water Quality

3. Pesticide Export Reform

4. Changes in the Federal Noxious Weed Act

5. Support of IR-4 (Minor Uses)

6. FIFRA Preemption

7. The USDA Competitive Research Grants Program

8. Herbicide Resistant Crops

\section{WHY SHOULD THE PUBLIC BE CONCERNED ABOUT WEEDS?}

- Combined losses and costs of weeds in the U.S. exceed $\$ 20$ billion per year.

- Growers spend more than $\$ 3$ billion annually for chemical (herbicides) weed control plus several times this amount for cultural and other methods of weed control.

- It is estimated that as many as 13 million people in the U.S. suffer from hay fever and asthma; much of it is caused by weeds.

- It is estimated that allergies lead to nearly 100 million days of restricted activity and approximately 40 million bed-disability days each year in the U.S. Weeds trigger many of these allergic reactions.

\section{POSITION STATEMENT THE USDA COMPETITIVE RESEARCH GRANTS PROGRAM}

- SITUATION: Weeds are the number one pest problem in U.S. agriculture. The economic loss due to weeds in the U.S., combined with the cost of their control, is estimated to be more than $\$ 20$ 
billion annually. These costs do not include the potential long-range cost of contamination of groundwater and surface water with herbicides which are required because there are no present alternative control strategies. Herbicides comprise more than $60 \%$ of all pesticides applied in this country. Thus, the cost of weeds to American agriculture and the American public is enormous. Many fundamental problems related to weeds must be solved to reduce these costs. Most of the problems are not of interest to the private sector because it is unlikely to benefit from their solution. Therefore, increased funding from government for fundamental and applied research on the physiology, ecology, genetics, biocontrol, biochemistry, molecular biology, and cell biology of weeds is necessary to provide new knowledge for the development of technological approaches to meet this costly challenge.

- PROBLEMS: Weed science, over the last 35 years, has advanced as a discipline from the work of a small group whose interest was primarily the study of herbicide use to a mature discipline encompassing areas of ecology, genetics, physiology, and biochemistry of weeds. Despite this growth some still question the relevance of this discipline. The cost of weeds to agriculture is at least one third the cost of all pests. Yet only $16.7 \%$ (in 1990) and 8.5\% (in 1991) of USDA Competitive Grants within the Plant PathologyWeed Science program have gone to weed science research. Weed science proposals are evaluated by panels containing a majority of plant pathologists and always chaired by a plant pathologist. The composition of these panels results in some unavoidable unfairness against weed science proposals and does not allow many important problems in weed science to be addressed. This is further compounded by a division of panel funds between molecular biology and physiology/ecology. As a consequence, the low potential for funding has discouraged many scientists from applying for funds for fundamental weed science research. The critical need for increased support of basic research in weed science still remains.

- RATIONALE AND RECOMMENDED ACTION: Our recommended action to remedy this problem is to create a separate panel for weed science proposals. Funded at a level of $\$ 1$ million per year, $(0.005 \%$ of annual losses due (to weeds), it would increase competitive grants funding for weed science by about four-fold. A separate panel of qualified weed scientists would improve the number and quality of proposals in the weed science area. This would allow the USDA competitive grants program to stimulate quality research in weed science that is of great importance to American agriculture. WSSA and its affiliated societies are willing and eager to cooperate with CSRS to achieve the recommended action.

For additional information contact Dr. Stephen C. Weller, Chair, WSSA Competitive Grants Committee. Phone 317-494-1333, FAX 317-4940391.

June, 1992

\section{POSITION STATEMENT CHANGES IN THE FEDERAL NOXIOUS WEED ACT}

Introduced noxious weeds have a dramatic effect on American agriculture, rangelands, wetlands and aquatic waterways through direct competition with desirable native plants and by interfering with crop production and other activities of man. As enacted, the Federal Noxious Weed Act of 1974 is designed to provide for the control, exclusion, and eradication of noxious weeds and to regulate their interstate movement. This Act should serve as the initial step in preventing the entry and spread of noxious weeds; however, various interpretations of the Act have created problems with enforcement and action alternatives at the federal and state level.

In order to ensure a more comprehensive approach to the protection of our agricultural and natural resources, WSSA recommends that the following amendments be made to the Federal Noxious Weed Act:

USDA should pursue adequate and stable funding to implement the full range of weed activities authorized and presently proposed for the Federal Noxious Weed Act.

Revise and expand the definition of noxious weeds, contained in Section 2 (c) of the Act, to include wetland weed species.

Establish a Noxious Weed Technical Advisory Group to evaluate candidate species, develop appropriate classification criteria for noxious weeds, 
and make recommendations essential to implement the Act.

Grant emergency authority to the APHIS Administrator to prohibit the entry of any foreign weeds which meet the definition of a federal noxious weed, but which have not been formally added to the list.

Insert appropriate language into Section 4 of the Act to prohibit the intentional movement of federal noxious weeds across state lines except under permit.

Outline an action classification system that categorizes the status of each federal noxious weed.

Delete the statement in Section 12 of the Act that exempts the regulation of shipments of agricultural and vegetable seeds.

For additional information contact Dr. Howard M. Singletary, Chair, WSSA Federal Noxious Weed Law and Regulatory Committee. Phone 919-733-3930, FAX 919-733-1041.

June, 1992

\section{POSITION STATEMENT FIFRA PREEMPTION}

Weed scientists can appreciate the desire of some local municipalities to establish ordinances for pesticide (including herbicide) use within their jurisdictions. However, there currently exists adequate federal as well as state jurisdiction with respect to regulation of pesticides in the United States to protect the general welfare of humans and other animals and the environment.

Centralization (e.g., federal and/or state) of pesticide jurisdiction or regulation oversight is essential and serves to prevent a myriad of rules or laws that will make the regulation of all pesticides, including herbicides, too cumbersome to serve the very purpose for which they were developed: this purpose being to manage pests, thereby permitting the production and availability of adequate food and fiber in desired quantity and quality.

Also, Federal and State authorities have available comprehensive scientific resources that are required to fully evaluate the extensive data base necessary to support the safety of pesticide products.

The Weed Science Society of America recommends that decisions and rulings relative to pesticides continue to be regulated by the U.S. Environmental Protection Agency under the authority of FIFRA (Federal Insecticide Fungicide and Rodenticide Act) or as specifically delegated to the individual states. We further recom- mend that local jurisdictions be permitted input into the federal/state pesticide regulations where local conditions justify a particular use ordinance.

For additional information contact Dr. Laura $L$. Whatley, Chair, WSSA Regulatory Committee. Phone 609-799-0400, FAX 609-275-0655.

June, 1992

\section{POSITION STATEMENT FOOD SAFETY}

- The United States' food supply is one of the most highly regulated and monitored in the world and also one of the world's safest. The WSSA supports the research and regulatory measures, which continue to improve the quality and quantity of our food supply while maintaining its availability and reasonable cost to the consumer. WSSA members are actively investigating both chemical and alternative weed management methods, which provide the maximum environmental and food safety benefits to the farmer and the public.

- Herbicides continue to be invaluable tools for maintaining the productivity of our farallands. Tolerance levels of herbicide residues in crops and processed food are established by the EPA and provide a wide margin of safety for consumers. Numerous, periodic surveys of our food supply show that herbicide residues are rarely detected and when detected are nearly always below the tolerance level.

- The crop yield benefits of managing weeds and the economic benefits of using herbicides to help accomplish weed management are well established. An additional benefit of chemical weed control is its integral role in the practice of conservation (reduced) tillage, which grestly reduces soil erosion. Furthermore, additional important benefits of managing weed infestations include improved food quality (nutrition, palatability, fewer defects), ease and safety of mechanical harvesting, reduced weed seed contamination and a reduction in alternative hosts for crop pests.

- Studies have consistently established the low risks compared to the great benefits to food safety posed by the use of herbicides in food production. The risk assessment process will continue to provide a large margin of safety for our food supply and it is important for agricultural professionals to 
help the public understand this process. The WSSA is happy to provide additional information and data on food safety and quality generated by university, government and industry scientists who make up our membership.

For additional information contact Dr. Janis McFarland, Chair WSSA Food Quality Committee. Phone 919-632-2354, FAX 919-632-7581.

June, 1992

\section{POSITION STATEMENT HERBICIDE-RESISTANT CROPS}

- Definition and Significance: Crops that are sensitive to certain herbicides can, in some cases, be made resistant by conventional plant breeding or genetic engineering. Herbicide-resistant crops allow the use of an alternative herbicide to provide new weed control options.

- Appropriate Use: Herbicide-resistant crops are often appropriate 1) in minor acreage crops, because of the economic barriers to herbicide registration, 2) where there are noxious weed problems that cannot otherwise be solved, 3) when the resistance trait allows the use of one herbicide in place of two or more, and 4) when the resistance trait will allow use of a herbicide that possesses significantly more favorable environmental and toxicological properties than the presently used herbicides (s).

- Inappropriate Use: Herbicide-resistant crops are generally not appropriate 1) when resistance is developed to herbicides with unfavorable environmental or toxicological properties, 2) when the crop lacks adequate genetic barriers to prevent outcrossing of resistance to weeds, and 3) when there are inadequate measures for control of the volunteer resistant crop.

- Risk: It is incorrect to assume that herbicideresistant crops will increase the risk to our environment or foot supply. In many cases the risk will be decreased.

- Legislation: Legislation to restrict reșearch on herbicide-resistant crops would penalize American agriculture with no real benefit to the public.

- Our Position: The WSSA advocates the integrated use of all approaches to weed management, including the use of cultural, mechanical, and biological control methods, as well as the judicious use of herbicides and herbicide-resistant crops.

For additional information contact Dr. Pat Fuerst. Phone 509-335-7484, FAX 509-335-8674.

June, 1992

\section{POSITION STATEMENT SUPPORT FOR IR-4 PROJECT}

- WSSA recommends increased support for the IR-4 Program-a Federally sponsored agricultural research program on minor uses of pesticides. IR4 coordinates and funds the efforts of scientists at state and federal experiment stations and laboratories to obtain required herbicide performance and residue data for food crops, and efficacy data for non-food uses. The activities are coordinated with the pesticide registrant.

- With the FIFRA re-registration process, planned for completion in 1997, an estimated $30 \%$ of currently registered pesticides will not be reregistered. Herbicide use in minor crops will be affected the most. Many manufacturers will not generate the necessary data to support re-registration of their products for fruits, vegetables, ornamentals, strawberries, tree plantations, and other minor herbicide uses. Consequently, more projects will be referred to IR-4 whose laboratories are working at capacity already. Currently, there is a backlog of 1200 requests for new minor use clearances.

- WSSA recommends continued USDA funding for IR-4 by means of a line item in the budget through PL 87-106 Special Grant monies. WSSA also recommends a minimum final budget of $\$ 14$ million per year for IR-4.

- Industry support could be obtained in some cases for re-registration of specific pesticides for minor uses if there was a standard mechanism to allow transfer of crop injury and efficacy liability to the growers who requested the information.

For additional information contact Dr. Joan Dusky, Chair, WSSA Herbicides for Minor Uses Committee. Phone 407-996-3062, FAX 407-9960339.

June, 1992 


\section{POSITION STATEMENT PESTICIDE EXPORT REFORM}

- WSSA recognizes that the responsible use of herbicides plays an essential role in effective weed management in most production systems, thereby helping to insure economic crop returns.

- WSSA endorses EPA's judicious regulation of herbicides on the basis of sound scientific evidence.

- WSSA strongly recommends that import and export of experimental and developmental unregistered herbicides continue to be permitted in the U.S. This is critical for the development of new environmentally sound herbicides for the U.S. that are synthesized by U.S. companies as well as off-shore companies.

- WSSA endorses the prevention of export and/or import of herbicides banned by the U.S. Environmental Protection Agency.

For additional information contact Dr. Henry Collins, Co-Chair, WSSA Legislative Committee. Phone 919-632-2172, FAX 919-632-2997.

June, 1992

\section{POSITION STATEMENT WATER QUALITY ISSUES}

- Groundwater Quality: Comprehensive DrinkingWater studies indicate low incidence of pesticide contamination. Four large studies-the EPA National Pesticide Survey, a nationwide survey by Monsanto, a 4-state survey by Ciba-Geigy, and an intensive survey in Germany-indicate that only a small number of pesticides were present in wells, and about $1 \%$ of wells sampled had levels of one pesticide at a health advisory level. The amounts that would be consumed are in general a very small fraction of those allowed in foods.

WSSA POSITION: These studies were designed in part to answer the question "how widespread is contamination of groundwater by pesticides?" We believe that continued monitoring, and efforts to decrease input of pesticides to water sources should continue. But these studies are strong evidence that pesticides are not widespread contaminants of groundwater or at levels that have been determined to be a health concern.

- Surface Water Quality: Studies indicate that herbicides in rivers in the Corn Belt and the Missis- sippi river system can exceed health advisory levels. The U.S. Geological Survey and the Missouri River Public Water Supplies Association have conducted studies in which corn belt river systems and the Mississippi/Ohio/Missouri river system were extensively analyzed for pesticides. In some basins, herbicide concentrations exceeded EPA Maximum Contaminant Levels (MCL's) during the "spring flush" of run-off immediately following herbicide application. Similarly, in the Mississippi river system, concentrations exceeding MCL's occurred during spring and early summer. WSSA POSITION: These findings indicate that the more widely used herbicides in the corn belt are entering important surface drinking water sources, at least in the period immediately after application. However, MCL's are based on continuous and lifetime exposure and include large safety factors. Based on other studies of annual patterns, it is likely that full-year monitoring will establish that the annual average concentrations for these herbicides are below the MCL's. Continued monitoring is essential.

- Pesticide Risk Reduction: Water pollution prevention education programs can be misused. Several federal and state agencies are using published tables of pesticide "water pollution potential indexes" to predict whether a pesticide may contaminate ground and surface water. These indexes give very rough estimates of pollution potential. They can be misused to favor one pesticide over others even when the diffenences in pollution potential are small. The procedure is not designed to, or capable of, making fine distinctions-it is much too crude an estimate. WSSA POSITION: Agencies using these procedures should emphasize that these screening procedures are to be used only to delineate "extremely likely to be safe" and "extremely likely to pollute" situations. Until the procedures can be refined and validated, they should not be used as regulatory tools but only provided to pesticide users as educational tools.

For additional information contact Dr. R. Don Wauchope, Chair, WSSA Water Quality Committee. Phone 912-386-3892, FAX 912-382-8092.

June, 1992 